\title{
PENGARUH SUBSTITUSI AGREGAT KASAR DENGAN PECAHAN BATU BATA KLINKER TERHADAP KUAT TEKAN BETON NORMAL
}

\author{
Yulius Rief Alkhaly, Fakhrur Rozi, M. Kabir Ihsan \\ Jurusan Teknik Sipil, Fakultas Teknik Universitas Malikussaleh \\ Email:yr.alkhaly@gmail.com
}

\begin{abstract}
Abstrak
Batu-bata klinker merupakan hasil dari produksi bata merah, namun mengalami kelebihan suhu saat proses pembakaran yang membuat bentuk dan ukurannya menjadi tidak beraturan. Batu bata ini tidak dapat digunakan sebagai bahan bangunan dan menjadi limbah yang dibuang. Selain berbobot ringan dan berwarna lebih gelapdari bata normal, kondisi fisik bata klinker lebih keras sehingga berpotensi dijadikan sebagai agregat pada pembuatan beton. Penelitian ini ditujukan untuk mengetahui besarnya kuat tekan beton normal pada substitusi agregat kasar dengan batu bata klinker. Sampel beton untuk pengujian kuat tekan berbentuk silinder dengan ukuran $150 \mathrm{~mm}$ x 300mm, berjumlah sebanyak 20 benda uji. Adukan beton dibuat berdasarkan faktor air semen 0,48, dan variasi substitusi bata klinker yaitu sebanyak 0\%, 25\%, 50\% dan $100 \%$ terhadap volume absolut adukan. Hasil penelitian menunjukkan kuat tekan beton normal (BN) pada nilai slump 6,5 cm didapat sebesar 22,54 MPa, untuk beton klinker 25\% (BK1) dengan slump $5 \mathrm{~cm}$ didapat kuat tekan 22,30 $\mathrm{MPa}$, untuk beton klinker 50\% (BK2) dengan slump $6 \mathrm{~cm}$ didapat kuat tekan 21,86 MPa, dan untuk beton klinker 100\% (BK3) dengan slump 5,5 cm didapat kuat tekan 21,74 MPa. Dari segi berat volume beton, BN memiliki bobot sebesar $2329,09 \mathrm{~kg} / \mathrm{m}^{3}$, sedangkan untuk BK1, BK2 dan BK3 berturut-turut berbobot $2262,34 \mathrm{~kg} / \mathrm{m}^{3}, 2210 \mathrm{~kg} / \mathrm{m}^{3}, 2122,50 \mathrm{~kg} / \mathrm{m}^{3}$. Penurunan bobot ini berkisar 2,87\% - 8,87\% dari bobot BN. Hasil penelitian memberi gambaran bahwa kuat tekan beton beragregat bata klinker masih dalam katagori kuat tekan yang disyaratkan, dan bobotnya lebih ringan dibanding beton normal. Berdasarkan hasil ini diketahui bata klinker berpotensi sebagai agregat kasar untuk pembuatan beton normal untuk aplikasi struktural.
\end{abstract}

Kata kunci: Agregat kasar, batu bata klinker, kuat tekan, beton normal.

\section{Pendahuluan}

Di Indonesia, dewasa ini bahan bangunan terbanyak digunakan pada konstruksi sipil adalah beton dengan klasifikasi jenis beton normal.Beton normal mempunyai nilai kuat tekan antara 17-40 MPa, umumnya material yang digunakan adalah kerikil/batu pecah sebagai agregat kasar dan pasir sebagai agregat halus.

Pada pembuatan adukan beton normal, penggunaan agregat berkisar antara $60 \%$ - $80 \%$ dari volume beton, sehingga pengaruh agregat akan menjadi sangat besar. Selain memberi bentuk pada beton dan memberi kekuatan guna menahan beban, penggunaan agregat juga bertujuan untuk keperluan ekonomis (Kosmatka, S. H., et.al, 2003). Penggunaan agregat dalam adukan beton terhitung relatif besar disetiap meter kubik produksi beton, sehingga hal ini berdampak pada eksploitasi material di alam, terutama pada daerah aliran sungai untuk penambangan kerikil dan pasir. 
Berdasarkan Aceh Utara Dalam Angka tahun 2011, di Kabupaten Aceh Utara diketahui penggunaan material dari sungai (kerikil/pasir) $\pm 665.603 \mathrm{~m}^{3}$ setiap tahunnya. Selanjutnya dari survey lapangan di Kecamatan Sawang, Kabupaten Aceh Utara, didapat informasi bahwa terjadi penurunan permukaan sungai setinggi $\pm 150 \mathrm{~mm}$ pada tiap tahunnya. Oleh karena itu, agar dapat mengurangi dampak kerusakan Daerah Aliran Sungai (DAS), maka perlu diusahakan penggunaan material alternatif dalam pembuatan beton.

Ada beberapa agregat alternatif yang dapat digunakan terutama bahan yang berasal dari limbah, misalnya pecahan genteng, pecahan keramik, pecahan beton, dan plastik (Batayneh, M., et. al., 2006). Adapun dalam penelitian ini digunakan material alternatif substitusi agregat kasar berupa batu bata klinker yang merupakan batu bata yang mengalami kelebihan suhu (over heated) saat proses pembakaran.Limbah batu bata klinker dapat menurunkan kesuburan tanah, yang pada tahap selanjutnya merusak kondisi lingkungan, karena batu bata klinker adalah benda keras dan tidak dapat terurai secara alami oleh lingkungan (nonbiodegradable). Timbunan batu bata klinker ini tidak dapat ditumbuhi oleh pepohonan. Pemanfaatan limbah untuk diolah kembali (recycle) merupakan cara penanganan pencemaran lingkungan yang dinilai tepat. Pemanfaatan batu bata klinker untuk pembuatan beton, diharapkan dapat mengurangi dampak buruk terhadap lingkungan, dan dapat memberi nilai ekonomis pada pembuatan beton.

\section{Tinjauan Kepustakaan}

\subsection{Batu Bata Klinker}

Batu bata klinker merupakan produk sampingan (by prodruct) dari pembuatan batu bata merah. Produk sampingan ini terjadi karena mengalami kelebihan suhu saat proses pembakaran dan bentuknya terdistorsi sehingga menjadi tidak layak untuk digunakan pada pekerjaan konstruksi. Bahan dasar Batu bata klinker sama seperti batu bata merah, antara lain terdiri dari: lempung, pasir dan air, hanya saja bata ini terbakar dengan suhu sangat tinggi sampai berwarna merah-kehitaman. Akibat dari suhu tinggi tersebut, batu bata klinker tidak akan hancur/lunak kembali walaupun direndam dalam air dalam jangka waktu lama. Selain itu, batu bata klinker juga mempunyai sifat fisik tajam, keras, dan kaku.Sifat batu bata tergantung pada lingkungan geologi lokasi bahan diambil.

Di Aceh Utara dan sekitarnya, proses produksi batu bata merah masih dilakukan dengan cara tradisional menggunakan alat-alat yang sederhana. Tanah liat atau tanah lempung yang telah dibersihkan dari kerikil atau bahan lain, diberi air dan diaduk menjadi adonan tanah. Adonan ini peram selama satu hari satu malam, kemudian dicetak dengan menggunakan cetakan dari kayu atau cetakan baja. Hasil cetakan ini disebut bata mentah/hijau. Setelah proses pencetakan selesai, bata mentah langsung dijemur untuk proses pengeringan selama 1-2 hari. Proses penjemuran tidak boleh terkena paparan sinar matahari langsung dan hujan. Tahap berikutnya dimaksukkan ke dalam tungku/dapur pembakaran (Gambar 1) dan disusun tegak pada sisi panjangnya gunungan dengan diberi celah-celah lobang agar pembakaran merata. Proses pembakarannya akan berkisar 1 - 2 hari tergantung jumlah bata yang dibakar atau sampai bata mentah berubah 
warna menjadi kemerah-merahan. Sebagian bata mentah yang disusun dekat dengan pintu/mulut tempat sumber api akan menjadi batu bata klinker. Suhu api pada saat pembakaran dapat mencapai $2000{ }^{\circ} \mathrm{C}$.

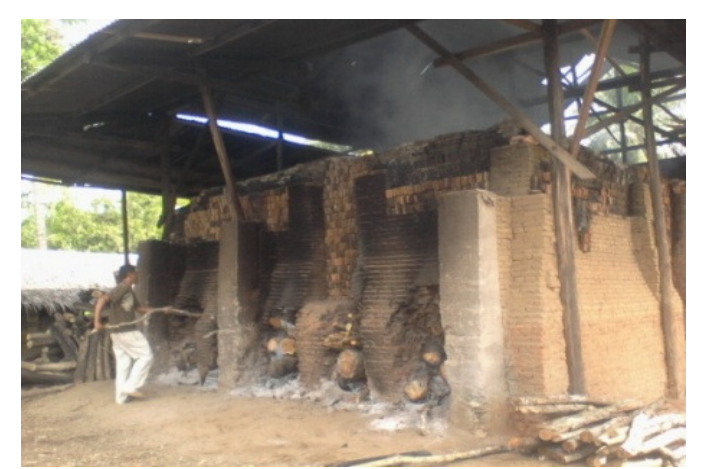

Gambar 1 Tungku/dapur pembakaran batu-bata

Batu bata klinker mempunyai dimensi yang tidak stabil dan sangat variatif sehingga tidak memenuhi ukuran standar batu bata merah sebagaimana dalamSNI-15-2094-2000. Ketidak-stabilan dimensi bata klinker dipengaruhi oleh pembakaran pada suhu tinggi, bentuk/ukurannya terdistorsi dan mengalami perubahan, misalnya: permukaanya bergelombang atau melengkung, pecah sudut dan melintir, serta tebalnya berbeda antara satu bagian dengan bagian yang lain. Sampel dari batu bata klinker dan perbandingannya dengan batu bata merah diperlihatkan pada Gambar 2.

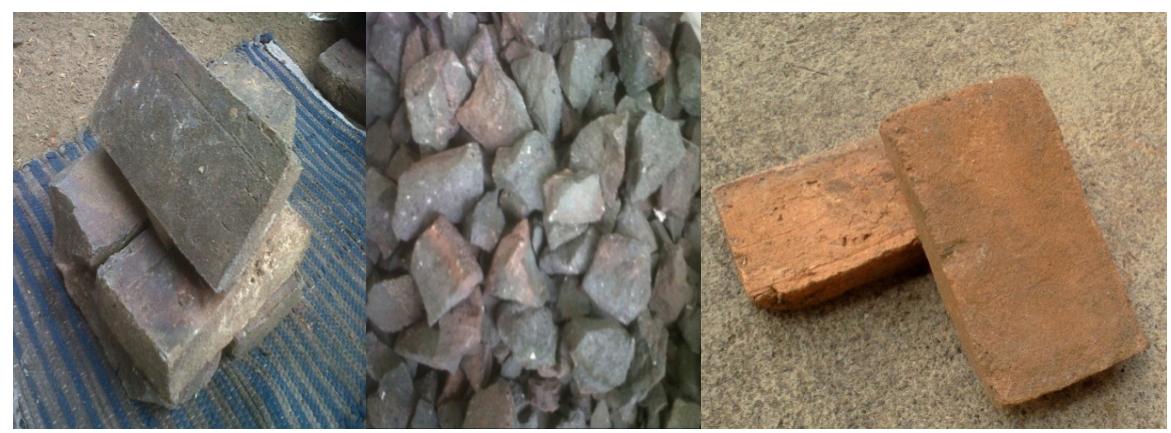

(a)

(b)

(c)

Gambar 2 (a) Batu bata klinker, (b)Pecahan batu bata klinker, (c) Batu bata merah

\subsection{Beton Normal}

\subsubsection{Definisi}

Beton normal merupakan beton yang paling umum digunakan pada struktur/ bangunan. Beton ini terbuat dari sement portland, air, pasir, dan kerikil/batu pecah. Beton normal dengan kuat tekan 17-40 MPa memiliki berat volume 2300$2400 \mathrm{~kg} / \mathrm{m}^{3}$ (SNI 03-2847-2002). Menurut Mulyono, T., 2004, kekuatannya sangat dipengaruhi faktor-faktor komposisi campuran, mutu bahan, kondisi temperatur tempat beton mengeras dan cara pembuatannya. Beton normal memiliki kelebihan dan kekurangannya, yaitu: 
a. Kelebihan:

- Dapat dengan mudah dibentuk sesuai dengan keperluan konstruksi;

- Mampu memikil beban yang besar;

- Tahan terhadap temperatur tinggi dan;

- Biaya pemelaharaan yang relatif kecil.

b. Kekurangan:

- Bentuk sulit diubah bila telah mengeras;

- Pelaksanaannya membutuhkan bekisting;

- Bobot berbanding kuat tekan relatif besar;

- Daya pantul suararelatif besar.

\subsubsection{Kuat Tekan}

Kuat tekan beton yang diisyaratkan $\mathrm{f}_{\mathrm{c}}$ adalah kuat tekan beton yang ditetapkan oleh perencana struktur dipakai dalam perencanaan struktur beton, dinyatakan dalam Mega Paskal atau MPa. Kuat tekan merupakan kemampuan beton dalam menerima gaya tekan persatuan luas penampang tanpa mengalami kerusakan. Kuat tekan sangat tergantung kepada faktor air semen (fas), bentuk dan ukuran benda uji, proporsi campuran, dan mutu material.

Menurut SNI 03-1974-1990, nilai kuat tekan beton didapatkan melalui tata cara pengujian standar, menggunakan mesin uji dengan cara memberikan beban tekan bertingkat dengan kecepatan peningkatan beban tertentu atas benda uji silinder beton (diameter $150 \mathrm{~mm}$, tinggi $300 \mathrm{~mm}$ ) sampai hancur. Rumus yang digunakan untuk menghitung kuat tekan dari benda uji sebagai berikut:

$$
\mathrm{f}_{\mathrm{c}}=P^{P} / \mathrm{A}
$$

Keterangan:

$$
\begin{aligned}
& \mathrm{f}^{\prime}{ }_{\mathrm{c}}=\text { kuat tekan }(\mathrm{MPa}) \\
& \mathrm{P}=\text { beban tekan maksimum }(\mathrm{N}) \\
& \mathrm{A}=\text { luas bidang tekan rata-rata }\left(\mathrm{mm}^{2}\right)
\end{aligned}
$$

\subsection{Agregat Kasar}

Agregat dinamakan agregat kasar apabila ukuran butirannya tertahan di ayakan/saringan $4,75 \mathrm{~mm}$. Ukuran butiran agregat kasar maksimum ditetapkan sebesar 40 mm (SNI 03-2847-2002).

Seluruh standar perancangan campuran beton memberi syarat bahwa butir agregat harus berada dalam rentang ukuran tertentu dan untuk masing-masing ukuran partikel harus dalam proporsi tertentu. Distribusi dari variasi ukuran butir agregat ini disebut gradasi agregat. Gradasi agregat mempengaruhi besarnya rongga dalam campuran dan menentukan kelecakan (workability, sifat mudah dikerjakan) dan konsistensi adukan. Gradasi agregat kasar dengan ukuran butir maksimum tertentu akan mempengaruhi besarnya proporsi dari material pembentuk beton lainnya, yaitu jumlah agregat halus, semen dan air.

Pengujian gradasi agregat dilakukan dengan menggunakan satu set ayakan. Ayakan dengan ukuran lubang paling besar diletakkan paling atas dan yang paling halus diletakkan paling bawah sebelum pan.Persyaratan gradasi agregat kasar berdasarkan SNI 03-2834-2002 disajikan dalam Tabel 1. 
Tabel 1 Persyaratan gradasi kerikil/batu pecah

\begin{tabular}{|c|c|c|c|}
\hline $\begin{array}{c}\text { Butir } \\
\text { maksimum }\end{array}$ & $10 \mathrm{~mm}$ & $20 \mathrm{~mm}$ & $40 \mathrm{~mm}$ \\
\hline Ukuran ayakan & $\%$ Lolos & $\%$ Lolos & \% Lolos \\
\hline $38,10 \mathrm{~mm}$ & 100 & 100 & $95-100$ \\
\hline $19,00 \mathrm{~mm}$ & 100 & $95-100$ & $37-70$ \\
\hline $9,52 \mathrm{~mm}$ & $50-85$ & $30-60$ & $10-40$ \\
\hline $4,75 \mathrm{~mm}$ & $0-10$ & $0-10$ & $0-5$ \\
\hline \multicolumn{4}{|c}{ Sumber: SNI 03-2834-2002 }
\end{tabular}

Selain syarat gradasi, agregat kasar juga harus memenuhi syarat mutu agar dapat digunakan sebagai material beton, yaitu:

- Butirannya tajam, kuat dan keras;

- Bersifat kekal, tidak pecah atau hancur karena pengaruh cuaca. Sifat kekal, apabila diuji dengan larutan jenuh garam sulfat sebagai berikut: ○ Jika dipakai natrium sulfat, bagian yang hancur maksimum $12 \%$ ○ Jika dipakai magnesium sulfat, bagian yang hancur maksimum $10 \%$

- Agregat kasar tidak boleh mengandung lumpur ( bagian yang dapat melewatiayakan $0,060 \mathrm{~mm}$ ) lebih dari $1 \%$. Apabila lebih dari $1 \%$ maka kerikil harus dicuci;

- Tidak boleh mengandung zat organik dan bahan alkali yang dapat merusak beton;

- Harus mempunyai variasi besar butir (gradasi) yang baik, sehingga rongganya sedikit;

- Tidak boleh mengandung garam;

\section{Metode Penelitian}

\subsection{Material}

Pada penelitian ini, semen yang digunakan adalah semen Portland tipe I produksi PT. Semen Andalas Indonesia.Pemeriksaan terhadap semen hanya dilakukan secara visual, semen dalam kondisi baru dan tidak ditemui gumpalangumpan.Air yang digunakan berasal dari Laboratorium Teknik Sipil, Universitas Malikussaleh.

Agregat halus yang digunakan berupa pasir sungai. Agregat kasar berupa batu pecah dan agregat klinker (pecahan batu bata klingker) dengan ukuran lolos saringan 19,0 $\mathrm{mm}$ dan tertahan pada saringan 4,75 $\mathrm{mm}$. Pasir dan batu pecah berasal dari desa Krueng Mane, Kabupaten Aceh Utara.Batu bata klingker diperoleh dari sebuah rumah produksi bata di Desa Ule Pulo, Kecamatan Dewantara, Kabupaten Aceh Utara.

\subsection{Penyiapan Agregat Klinker}

Agregat klinker diperoleh dengan cara pemecahan batu bata klinker yang dilakukan secara manual. Pemecahan dilakukan sedemikian rupa sehingga didapat bentuk pecahan yang bersudut (Gambar 2b) dan tidak beraturan dengan ukuran 4,75 mm sampai $19 \mathrm{~mm}$. Ukuran lebih kecil dari 4,75 mm tidak digunakan. Adapun hasil analisa saringan agregat diperlihatkan pada tabel berikut: 
Tabel 2 Analisa saringan agregat

\begin{tabular}{|c|c|c|c|}
\hline \multirow{2}{*}{$\begin{array}{c}\text { Ukuran saringan } \\
(\mathrm{mm})\end{array}$} & \multicolumn{3}{|c|}{ \% Lolos } \\
\cline { 2 - 4 } & Klinker & Batu Pecah & Pasir \\
\hline 38,10 & 100,00 & 100,00 & 100 \\
\hline 19,00 & 100,00 & 100,00 & 100 \\
\hline 12,7 & 49,55 & 84,69 & - \\
\hline 9,50 & 24,71 & 47,39 & 100,00 \\
\hline 4,75 & 0 & 0 & 100,00 \\
\hline 2,36 & 0 & 0 & 87,85 \\
\hline 1,18 & 0 & 0 & 67,17 \\
\hline 0,6 & 0 & 0 & 40,42 \\
\hline 0,3 & 0 & 0 & 13,30 \\
\hline 0,15 & 0 & 0 & 2,83 \\
\hline Modulus halus butir & 2,25 & 1,67 & 2,88 \\
\hline
\end{tabular}

Sifat fisis lainnya dari agregat diperlihatkan dalam tabel berikut:

Tabel 3 Sifat fisis agregat

\begin{tabular}{|c|c|c|c|c|}
\hline \multicolumn{2}{|c|}{ Uraian } & Klinker & Batu Pecah & Pasir \\
\hline & 19,00 & 19,00 & 4,75 \\
\hline \multirow{2}{*}{$\begin{array}{l}\text { Berat } \\
\text { Jenis }\end{array}$} & Kering jenuh-permukaan & 2,17 & 2,66 & 2,50 \\
\hline & Kering tungku/oven & 2,15 & 2,64 & 2,42 \\
\hline \multicolumn{2}{|c|}{ Absorpsi (\%) } & 0,64 & 0,87 & 3,37 \\
\hline \multicolumn{2}{|c|}{ Kadar lembab (\%) } & 1,29 & 1,06 & 1,48 \\
\hline
\end{tabular}

\subsection{Benda Uji Beton}

\subsubsection{Komposisi Campuran}

Perancangan komposisi campuran beton (mix design) mengacu pada SNI 03-2834-2002, substitusi batu pecah dengan klinker diperhitungan dengan metode volume absolut. Persentase agregat klinker yang disubstitusikan ke dalam adukan beton sebesar 25\%, 50\%, dan 100\%. Kuat tekan rencana sebesar $20 \mathrm{MPa}$ dengan target slump $25 \mathrm{~mm}-100 \mathrm{~mm}$. Bobot material untuk masing-masing jenis beton diperlihatkan pada Tabel 4 berikut:

Tabel 4 Komposisi material per $\mathrm{m}^{3}$ beton

\begin{tabular}{|c|c|c|c|c|c|c|c|c|}
\hline \multirow{3}{*}{ Jenis Beton } & \multirow{3}{*}{ Kode } & \multicolumn{7}{|c|}{ Berat material untuk volume $1 \mathrm{~m}^{3}$, Fas 0,48} \\
\hline & & \multirow{2}{*}{$\begin{array}{c}\text { Semen } \\
(\mathrm{Kg})\end{array}$} & \multicolumn{2}{|c|}{ Klinker } & \multirow{2}{*}{$\begin{array}{c}\text { Batu } \\
\text { pecah } \\
(\mathrm{Kg})\end{array}$} & \multirow{2}{*}{$\begin{array}{l}\text { Pasir } \\
(\mathrm{kg})\end{array}$} & \multirow{2}{*}{$\begin{array}{l}\text { Air } \\
(\mathrm{Kg})\end{array}$} & \multirow{2}{*}{$\begin{array}{l}\text { Jumlah } \\
\text { Sampel }\end{array}$} \\
\hline & & & $(\mathrm{Kg})$ & $(\%)$ & & & & \\
\hline Beton Normal & $\mathrm{BN}$ & 406 & - & $0 \%$ & 1058,91 & 728,07 & 207,02 & 5 \\
\hline Beton Klinker 1 & BK1 & 406 & 217,81 & $25 \%$ & 797,11 & 728,07 & 209,13 & 5 \\
\hline Beton Klinker 2 & $\mathrm{BK} 2$ & 406 & 435,51 & $50 \%$ & 529,39 & 728,07 & 205,21 & 5 \\
\hline Beton Klinker 3 & BK3 & 406 & 871,03 & $100 \%$ & - & 728,07 & 202,39 & 5 \\
\hline
\end{tabular}

\subsubsection{Penyiapan dan Perawatan Benda Uji}

Masing-masing campuran beton menurut jenisnya diaduk menggunakan molen laboratorium kapasitas kecil bertipe drum. Pengadukan, pengecoran dan perawatan benda uji sesuai dengan standar ASTM C192. Setiap benda uji di cor menggunakan cetakan silinder baja standar berukuran $150 \mathrm{~mm}$ x $300 \mathrm{~mm}$ 
sebanyak 5 benda uji untuk masing-masing jenis beton. Pengecoran ini dilakukan dalam 3 lapisan, yang masing-masing lapisan dipadatkan dengan batang penumbuk sebanyak 25 kali. Pada tahap akhir pengecoran, permukaan benda uji diberi lapisan pasta semen agar menjadi rata dan halus, hal ini dilakukan setelah 4 jam dari pengecoran.

Semua benda uji yang berjumlah 20 buah dilepas dari cetakan baja setelah berumur 24 jam, kemudian dilakukan perawatan dengan cara perendaman dalam air pada suhu ruangan selama 28 hari.

\subsubsection{Prosudur uji tekan}

Pada umur 28 hari, seluruh benda uji dikeluarkan dari tempat perendaman, kemudian dibersihkan dari air yang membasahi dan ditimbang beratnya. Pengujian kuat tekan dilakukan berdasarkan ketentuan dalam SNI 03-1974-1990. Untuk pengujian kuat tekan digunakan mesin uji tekan hidrololik berkapasitas 2000 kN merek Tatonas (Gambar 3) yang telah dikalibrasi oleh KAN (Komite Akreditasi Nasional) Indonesia.

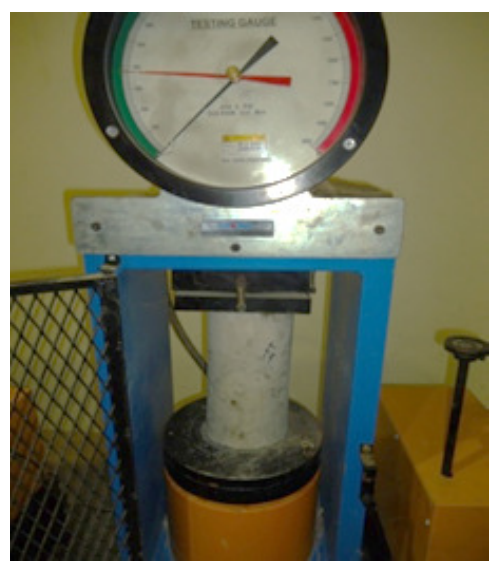

Gambar 3 Mesin Uji Tekan

\section{$4 \quad$ Hasil dan Pembahasan}

\subsection{Pengukuran Tinggi Slump}

Tinggi slump diukur sesuai denganAmerican Society for Testing and Materials (ASTM) C 143/C 143M - 03. Tinggi slump merupakan salah satu indikator bahwa adukan beton segar memiliki kelecakan dan kemudahan kerja (workability) tingkat tertentu. Makin besar nilai slump makin mudah beton segaruntuk diaduk, dipadatkan dan diratakan (funishing). Adapun hasil pengukuran tinggi slump untuk masing-masing variasi benda uji adalah sebagai berikut:

Tabel 5 Nilai slumpadukan beton

\begin{tabular}{|c|l|c|c|}
\hline No & Jenis Beton & Kode & $\begin{array}{c}\text { Rerata Tinggi } \\
\text { Slump }(\mathrm{mm})\end{array}$ \\
\hline 1 & Beton Normal & BN & 65 \\
\hline 2 & Beton Klinker1 & BK1 & 50 \\
\hline 3 & Beton Klinker 2 & BK2 & 60 \\
\hline 4 & Beton Klinker 3 & BK3 & 55 \\
\hline
\end{tabular}


Dari Tabel 5 diketahui bahwa substitusi agregat klinker terhadap batu pecah tidak memberi dampak yang besar pada turunnya nilai slump. Nilai slump untuk seluruh jenis beton cukup memenuhi syarat slump rencana $25 \mathrm{~mm}-100 \mathrm{~mm}$.

\subsection{Berat Sampel dan Kuat Tekan}

Tabel 6 memperlihatkan rangkuman berat sampel dan kuat tekan dari masing-masing jenis beton pada umur 28 hari. Beton normal (BN) sebagai kontrol memiliki kuat tekan rerata dari 5 sampel sebesar 22,55 MPa. BK1, BK2 dan BK3 merupakan beton dengan kandungan agregat klinker masing-masing sebesar 25\%, $50 \%$, dan $100 \%$ menunjukkan penurunan kuat tekan yang tidak signifikan dibanding BN.

Tabel 6 Berat dan kuat tekan masing-masing sampel beton

\begin{tabular}{|c|c|c|c|c|c|c|c|c|c|}
\hline $\begin{array}{l}\text { Kode } \\
\text { Jenis } \\
\text { Beton }\end{array}$ & $\begin{array}{l}\text { No } \\
\text { Uji }\end{array}$ & $\begin{array}{c}\text { Berat } \\
\text { Sampel } \\
(\mathrm{Kg})\end{array}$ & $\begin{array}{c}\text { Rerata } \\
\text { Berat } \\
\text { Sampel } \\
(\mathrm{Kg})\end{array}$ & $\begin{array}{c}\text { Varian }{ }^{*} \\
\text { Berat } \\
(\mathbf{V B}) \\
(\%)\end{array}$ & $\begin{array}{l}\text { Kuat } \\
\text { Tekan } \\
(\mathrm{MPa})\end{array}$ & $\begin{array}{c}\text { Standar } \\
\text { Deviasi } \\
\text { Kuat } \\
\text { Tekan }\end{array}$ & $\begin{array}{c}\text { Rerata } \\
\text { Kuat } \\
\text { Tekan } \\
\text { (MPa) }\end{array}$ & $\begin{array}{c}\text { Varian }^{*} \\
\text { Kuat } \\
\text { Tekan } \\
(\text { VK) } \\
(\%) \\
\end{array}$ & $\begin{array}{l}\text { VB / } \\
\text { VK }\end{array}$ \\
\hline \multirow{5}{*}{$\mathrm{BN}$} & 1 & 12,213 & \multirow{5}{*}{12,344} & \multirow{5}{*}{100,00} & 24,91 & \multirow{5}{*}{1,71} & \multirow{5}{*}{22,55} & \multirow{5}{*}{100,00} & \multirow{5}{*}{1,00} \\
\hline & 2 & 12,310 & & & 22,64 & & & & \\
\hline & 3 & 12,468 & & & 20,42 & & & & \\
\hline & 4 & 12,275 & & & 23,26 & & & & \\
\hline & 5 & 12,455 & & & 21,51 & & & & \\
\hline \multirow{5}{*}{ BK1 } & 1 & 12,067 & \multirow{5}{*}{11,990} & \multirow{5}{*}{97,13} & 23,77 & \multirow{5}{*}{1,95} & \multirow{5}{*}{22,30} & \multirow{5}{*}{98,89} & \multirow{5}{*}{0,98} \\
\hline & 2 & 11,980 & & & 21,51 & & & & \\
\hline & 3 & 12,115 & & & 24,91 & & & & \\
\hline & 4 & 11,920 & & & 20,38 & & & & \\
\hline & 5 & 11,870 & & & 20,94 & & & & \\
\hline \multirow{5}{*}{$\mathrm{BK} 2$} & 1 & 11,875 & \multirow{5}{*}{11,709} & \multirow{5}{*}{94,85} & 23,26 & \multirow{5}{*}{1,12} & \multirow{5}{*}{21,86} & \multirow{5}{*}{96,94} & \multirow{5}{*}{0,98} \\
\hline & 2 & 11,720 & & & 22,64 & & & & \\
\hline & 3 & 11,655 & & & 21,51 & & & & \\
\hline & 4 & 11,595 & & & 20,38 & & & & \\
\hline & 5 & 11,700 & & & 21,51 & & & & \\
\hline \multirow{5}{*}{ BK3 } & 1 & 11,260 & \multirow{5}{*}{11,258} & \multirow{5}{*}{91,20} & 20,94 & \multirow{5}{*}{1,17} & \multirow{5}{*}{21,74} & \multirow{5}{*}{96,41} & \multirow{5}{*}{0,95} \\
\hline & 2 & 11,305 & & & 23,21 & & & & \\
\hline & 3 & 11,287 & & & 20,38 & & & & \\
\hline & 4 & 11,090 & & & 21,51 & & & & \\
\hline & 5 & 11,348 & & & 22,64 & & & & \\
\hline
\end{tabular}

*) varian berat dan varian kuat tekan dihitung berdasarkan perbandingan rerata terhadap BN.

Penurunan kuat tekan pada BK1, BK2 dan BK3 hanya berkisar 0,25 MPa $0,81 \mathrm{MPa}$, atau berdasarkan Tabel 6 penurunan kuat tekan hanya sebesar 1,11\% sampai 3,59\% . Dalam hal ini berarti substitusi batu pecah dengan agregat klinker masih mampu mepertahankan kuat tekan rencana dari mix design, yaitu $20 \mathrm{MPa}$. 
Tabel 7 Perbandingan penurunan berat dan penurunan kuat tekan

\begin{tabular}{|c|c|c|c|c|c|}
\hline $\begin{array}{c}\text { Kode Jenis } \\
\text { Beton }\end{array}$ & $\begin{array}{c}\text { Rerata } \\
\text { Berat } \\
\text { Sample } \\
(\mathrm{Kg})\end{array}$ & $\begin{array}{c}\text { Berat } \\
\text { Volume } \\
\text { Beton } \\
\left(\mathrm{Kg} / \mathrm{m}^{3}\right)\end{array}$ & $\begin{array}{c}\% \\
\text { Penurunan } \\
\text { Berat }\end{array}$ & $\begin{array}{c}\text { Rerata } \\
\text { Kuat } \\
\text { Tekan } \\
(\mathrm{MPa})\end{array}$ & $\begin{array}{c}\% \\
\text { Penurunan } \\
\text { Kuat } \\
\text { Tekan }\end{array}$ \\
\hline BN & 12,344 & 2329,09 & 0,00 & 22,55 & 0,00 \\
\hline BK1 & 11,990 & 2262,34 & 2,87 & 22,30 & 1,11 \\
\hline BK2 & 11,709 & 2210,00 & 5,15 & 21,86 & 3,06 \\
\hline BK3 & 11,258 & 2122,50 & 8,80 & 21,74 & 3,59 \\
\hline
\end{tabular}

Sejalan dengan penurunan kuat tekan, Tabel 7 memperlihatkan BK1, BK2 dan BK3 memiliki bobot yang lebih ringan dibanding $\mathrm{BN}$, dengan rentang penurunan bobot sebasar $2,87 \%$ sampai $8,8 \%$. Dilihat dari perbandingan berat terhadap kuat tekan (VB/VK) pada Tabel 6, dengan mengacu BN sebagai kontrol yang bernilai 1, maka BK1, BK2 dan BK3 memiliki VB/VK lebih kecil dari BN dengan nilai masing-masing 0,$98 ; 0,98$; dan 0,95 . Nilai ini memberi gambaran bahwa berat volume beton berbanding kuat tekannya semakin baik dengan semakin bertambahnya persentase substitusi agregat klinker terhadap batu pecah pada beton $\mathrm{BN}$.

Hasil penelitian ini menunjukkan bahwa substitusi agregat kasar (batu pecah) dengan agregat klinker mampu mempertahankan performance kuat tekan beton, dan meningkatkan rasio kekuatan terhadap berat volume beton.

\section{$5 \quad$ Kesimpulan dan Saran}

\subsection{Kesimpulan} berikut:

Berdasarkan uraian di atas maka dapat diambil beberapa kesimpulan sebagai

1. Substitusi agregat kasar berupa agregat klinker (pecahan batu bata klinker) sebanyak $100 \%$ dalam adukan beton, mampu memenuhi kuat tekan rencana 20 MPa dan dapat dikatagorikan sebagai beton struktural;

2. Pada Fas 0,48, seluruh jenis beton beragregat klinker memiliki kemudahan kerja (workabily) yang baik;

3. Berat volume beton tereduksi sebesar $8,8 \%$ pada penggunaan $100 \%$ agregat klinker dibanding dengan batu pecah, sehingga rasio kekuatan terhadap berat volume meningkat. Namun demikian, beton agregat klinker tidak dapat dikatagorikan sebagai beton ringan, karena berat volumenya masih di atas 2000 $\mathrm{kg} / \mathrm{m}^{3}$.

\subsection{Saran}

Berdasarkan hasil penelitian dan pembahasan maka dapat diberikan saran-saran sebagai bentuk rekomendasi sebagai berikut:

1. Penelitian ini hanya berfokus pada sifat mekanis kuat tekan saja, maka perlu adanya kajian lanjutan terhadap sifat mekanis beton yang lain dan dengan beragam penggunaan ukuran agregat klinker maksimum;

2. Untuk mendapatkan hasil yang lebih baik, perlu dilakukan idealisasi/pengaturan terhadap susunan gradasi agregat klinker. 


\section{Daftar Kepustakaan}

Anonim, 1990, SNI 03-1974-1990: Metode Pengujian Kuat Tekan Beton, Badan StandarisasiNasional Indonesia;

Anonim, 2000, SNI 15-2094-2000:Bata Pejal Untuk Pasangan Dinding,Badan Standar Nasional Indonesia, Jakarta

Anonim, 2002a, SNI 03-2834-2002: Tata Cara Pembuatan Rencana Campuran Beton Normal, Badan Standarisasi Nasional Indonesia;

Anonim, 2002b, SNI 03-2847-2002:Tata Cara Perhitungan Struktur Beton Untuk Bangunan Gedung, Badan Standarisasi Nasional Indonesia;

Anonim, 2003a, American Society for Testing and Materials,ASTM C 192/C 192M - 02:Standard Practice for Making andCuring Concrete Test Specimens in TheLaboratory, ASTM International, United States;

Anonim, 2003b, American Society for Testing and Materials, ASTMC143/C 143M - 03:Standard Test Method for Slump of Hydraulic-Cement Concrete, ASTM International, United States;

Anonim, 2011, Aceh Utara Dalam Angka Tahun 2011, Badan Pusat Statistik, Kabupaten Aceh Utara;

Batayneh, M., et. al., 2006, Use of Selected Waste Materials in Concrete Mixes, Waste Management Vol. 27,pp. 1870-1876,

Mulyono, T., 2004, Teknologi Beton, Penerbit Andi, Yoyakarta.

Nugraha,P., 2007, Teknologi Beton, Penerbit Andi, Yogyakarta.

Kosmatka, S.H., et. al., 2003, Design and Control of Conctere Mixtures, edisi ke-14, Portland Cement Association, Illinois. 